\title{
AS TIC's COMO ESTRATÉGIA PARA AUMENTAR O CAPITAL SOCIAL E PROMOVER O EMPODERAMENTO E EMANCIPAÇÃO DO CAMPESINATO
}

Paulo Roberto Rosa, Munir Jorge Felicio

Universidade do Oeste Paulista - UNOESTE, Mestrado em Meio Ambiente e Desenvolvimento Regional (MMADRE), Presidente Prudente, SP. E-mail: paulorosapp@hotmail.com

\section{RESUMO}

O embate envolvendo capital e campesinato pelo domínio dos meios e modos de produção denomina-se Questão Agrária. O capital busca subordinar o campesinato através da expropriação da terra, enquanto o campesinato desenvolve estratégias para enfrentar essas investidas do capital e manter sua autonomia e protagonismo. Objetivou-se promover uma análise sobre como as Tecnologias da Informação e Comunicação (TIC's) podem contribuir para aumentar o estoque de capital social do campesinato e promover o seu empoderamento e autonomia. A revisão bibliográfica permitiu estabelecer a política pública de acesso e utilização de tecnologias como um canal efetivo para impulsionar a inclusão social e o jeito camponês de fazer agricultura. Possibilitou compreender que, embora o campesinato esteja parcialmente incluído no uso das TIC's, a realidade atesta que esse nível de inclusão é mantido em um patamar que não empodera e tampouco possibilita a emancipação do campesinato.

Palavras-chave: Campesinato, Capital Social, Empoderamento, Autonomia, Protagonismo.

\section{THE ICT'S AS A STRATEGY TO INCREASE THE SOCIAL CAPITAL AND PROMOTE EMPOWERMENT AND EMANCIPATION OF THE PEASANTRY}

\begin{abstract}
The clash involving capital and peasantry for the control of the means and modes of production is called Agrarian Issue. The capital seeks to subordinate the peasantry through the expropriation of the land, while the peasantry develops strategies to face this maneuvers form the capital and to maintain its autonomy and protagonist role. The purpose was to promote an analysis of how the Information and Communication Technologies (ICT's) may contribute to increase the social capital stocking of the peasantry and promote is empowerment and autonomy. The literature review allowed us to establish the public policy of access and use of technology as an effective channel to promote social inclusion and the peasant way of doing agriculture. It enabled us to comprehend that, even though the peasantry is partially included in the ICT's, the reality shows that this level of inclusion is maintained in a place that does not empower and also does not allows the emancipation of the peasantry.
\end{abstract}

Key words: Peasantry, Social Capital, Empowerment, Autonomy, Protagonist. 


\section{INTRODUÇÃO}

O campesinato luta historicamente por autonomia, protagonismo, controle sobre os meios e modos de produção, e contra as investidas do capital sobre a agricultura. O capital, por sua vez, busca expropriar o campesinato dos meios de produção para sujeitá-lo aos seus ditames, integrando ou tornando-o um proletário, que deixa de ser produtor de gêneros para sua própria subsistência e torna-se um consumidor de mercadorias. Para resistir, recriar-se e reproduzir-se o campesinato desenvolve suas próprias estratégias, muitas das quais incompreensíveis sob a ótica do capital.

$\mathrm{Na}$ tentativa de contribuir com a identificação de alternativas que colaborem para o desenvolvimento do campesinato, realizou-se uma análise sobre como as Tecnologias da Informação e Comunicação (TIC's) podem tornar-se uma aliada do campesinato nesse processo. A perspectiva é de que as TIC's, quando corretamente apropriadas e incorporadas, podem contribuir sobremaneira para aumentar o estoque de capital social e para promover o empoderamento e emancipação do campesinato. Foi realizada revisão bibliográfica com autores como Fernandes (2008), Felicio (2011), Motta (2005), através dos quais o fornecimento como política pública de acesso e utilização de tecnologias, as mais diversas, entre elas as TIC's, como um canal efetivo para impulsionar tanto a inclusão social quanto o desenvolvimento do jeito camponês de fazer agricultura. Objetivase apresentar razões e justificativas por intermédio das quais as TIC's podem contribuir significativamente com o desenvolvimento do campesinato, indicando, por exemplo, a melhor época do ano para o plantio.

\section{DELINEAMENTO CONCEITUAL}

A questão agrária é complexa e surge com o desenvolvimento da sociedade capitalista e o sistema de produção a ela relacionado. Segundo Fernandes (2008, p. 176) "a questão agrária nasceu da contradição estrutural do capitalismo que produz simultaneamente a concentração da riqueza e a expansão da pobreza e da miséria". Para Felício (2011, p. 6) "os elementos estruturantes da questão agrária se constituem pelo campesinato e pelo capital". Envolve uma relação conflituosa caracterizada pela disputa entre campesinato e capital pelo domínio dos meios de produção (terra, trabalho e tecnologia), ou seja, tudo aquilo que seja capaz de produzir riqueza.

A questão agrária decorre da concentração fundiária, tendo, de um lado pouca gente com muita terra e, de outro, muita gente com pouca ou nenhuma terra. 
No Brasil essa concentração tem origem na concessão de terra, pelo Estado, a um pequeno número de pessoas privilegiadas, ou então através da expropriação do campesinato pelo capital. "Por essa razão, a questão agrária gera continuamente conflitualidade, porque é movimento de destruição e recriação de relações sociais: de monopólio do território camponês pelo capital" (FERNANDES, 2008, p. 177).

A necessária delineação conceitual do campesinato e das sociedades camponesas, como forma de compreender a realidade que os envolve, foi destacada por Shanin (1979). Ele enfatiza que as sociedades camponesas são estruturas sociais muito complexas, dotadas de baixa organização formal, e, por isso, uma definição baseada em apenas um critério é insuficiente. Shanin (1979) estabeleceu quatro critérios básicos para delimitar as sociedades camponesas:

1. A propriedade familiar camponesa como a unidade básica de uma organização social multidimensional. A família, e quase só a família, contribui no trabalho da propriedade. [...]. 2. A agricultura como o principal meio de subsistência para atender à maioria das necessidades de consumo. [...] A produção de alimentos torna relativamente autônoma a propriedade familiar. [...]. 3. Uma cultura tradicional específica relacionada com o estilo de vida das pequenas comunidades. [...]. 4. A posição de subordinação e a dominação do campesinato por forasteiros (SHANIN, 1979 , p. 11-12. Grifos no original. Tradução minha).

O que diferencia a unidade camponesa da capitalista são: tipo de mão de obra empregada (familiar), forma de exploração da terra (produção poli cultural) e finalidade produtiva (voltada à subsistência e excedentes produtivos direcionados ao mercado interno). A terra é considerada local de trabalho, não de exploração, e a propriedade não tem como finalidade uma atividade de negócio. Chayanov (1974, p. 338. Tradução minha) estabelece que "a família deste tipo de unidade pode não coincidir com a família nuclear, já que pode incluir filhos, netos e membros 'adotados' pela família [...], e pode excluir membros da própria família que trabalhem noutro lugar".

Em suas análises Motta (2005, p. 73) assevera que "apesar da crença razoavelmente generalizada no fim inexorável do campesinato, isso não chegou a ocorrer. Camponeses ainda existem mesmo em sociedades modernas". Por isso, destaca a necessária capacidade evolutiva e adaptativa dos conceitos, devem ser flexíveis a ponto de acompanhar as transformações da realidade social. Motta (2005) considera os termos campesinato e camponês sinônimos e, apesar das diversas definições existentes para o camponês, destaca que todas elas convergem em três pontos 
comuns e interconectados: a) acesso a de terra para produzir; b) produção a partir da força de trabalho familiar; e c) a unidade camponesa como unidade de produção e consumo, simultaneamente. Neste texto o termo campesinato é compreendido como o grupo composto por pequenos produtores rurais, assentados e trabalhadores rurais assalariados.

O conceito de capital social aproximase de uma relação de reciprocidade com a vizinhança característica da unidade camponesa, onde os camponeses ajudam-se mutuamente na certeza de que haverá a retribuição dos vizinhos quando necessária. Nas análises de Putnam (2002, p. 177) "o capital social diz respeito a características da organização social, como confiança, normas e sistemas, que contribuam para aumentar a eficiência da sociedade, facilitando as ações coordenadas". Articular sistemas, relações e ações, com a construção de redes interconectadas de colaboração, é o desafio para proporcionar ao campesinato maior empoderamento e autonomia.

As TIC's são instrumentos que permitem automatizar máquinas e processos, bem como a captação, tratamento, armazenamento e disseminação de informações. Essas tecnologias dividem-se em dois grandes grupos: o hardware (a parte física, material) e o software (a parte lógica, imaterial), sendo que o último é responsável por fazer com que o primeiro desempenhe suas funções. Baltzan e Phillips (2012, p. 9) definem as TIC's como "um campo dedicado no uso da tecnologia, no gerenciamento e no processamento da informação".

\section{AS TIC'S COMO ALIADA NO DESENVOLVIMENTO DO CAMPESINATO}

O domínio das TIC's é importante para que o campesinato possa incorporar corretamente e tirar o máximo proveito da maquinaria disponível para aplicação nas atividades rurais. Entretanto, é necessário enfatizar também que essas tecnologias podem aproximar virtualmente as unidades camponesas, melhorando o seu interrelacionamento, promovendo o compartilhamento de informações e estreitando os laços de cooperação. Isso favorece sobremaneira as relações de reciprocidade e confiança através da construção de redes virtuais de colaboração do campesinato.

As relações de reciprocidade, honestidade e confiança são fundamentais para romper com 0 individualismo engendrado pelo sistema de produção capitalista. Em outras palavras, tem potencial para maximizar o estoque de capital social do campesinato. Bordieu (2012, p. 67) assevera que "o volume de capital social que um agente individual possui depende da extensão da rede de relações que ele pode 
efetivamente mobilizar e do volume do capital (econômico, cultural ou simbólico) que é posse exclusiva de cada um daqueles a quem está ligado".

O empoderamento está diretamente relacionado a extensão da rede de relações e ao grau de confiança, reciprocidade e articulação entre os participantes, sendo a confiança elemento indispensável à constituição do capital social. Arrow apud Putnam (2002) assevera: "pode-se muito bem afirmar que boa parte do atraso econômico no mundo se deve à falta de confiança" (ARROW apud PUTNAM, 2002, p. 180). É comum uma pessoa colocar em dúvida se a outra é confiável, mas "para haver cooperação é preciso não só confiar nos outros, mas também acreditar que se goza da confiança dos outros" (GAMBETTA apud PUTNAM, 2002, p. 174).

O capital social é fundado no sujeito, nas pessoas que possibilitam a transição do material para o imaterial; em elementos, interações e articulações sobre os quais não se aplicam as lógicas capitalistas de mensuração e valorização. $\mathrm{O}$ trabalho imaterial "repousa sobre as capacidades expressivas e cooperativas que não se podem ensinar, sobre uma vivacidade presente na utilização dos saberes e que faz parte da cultura do cotidiano" (GORZ, 2005, p. 19).

O que conta é a inteligência, a imaginação e o saber, ou seja, como se articula e o que se é capaz de fazer com os saberes acumulados e os novos conhecimentos adquiridos. Gorz (2005) desvincula o saber do conhecimento, pois este pode ser externalizado e documentado, o que não o torna menos importante, ao passo que "o saber é, antes de tudo, uma capacidade prática, uma competência que não implica necessariamente conhecimentos formalizáveis, codificáveis" (GORZ, 2005, p. 32). Para Gorz (2005, p. 9) "a informatização revalorizou as formas de saber que não são substituíveis, que não são formalizáveis".

A relação direta entre o saber e o capital social é estabelecida por Gorz (2005) ao colocar o saber "como atividade social que constrói relações comunicativas, não submetidas a um comando" (GORZ, 2005, p. 12). São justamente esses traços que caracterizam a cultura camponesa e o seu jeito peculiar de fazer agricultura. Como as práticas agroecológicas do campesinato objetivam colocar limites ao avanço do capital na agricultura, elas são "cientificamente" combatidas, marginalizadas, descaracterizadas e/ou desqualificadas. Seus resultados não são reconhecidos pela academia que os considerada como uma anomalia.

Isso se deve ao fato de que a ciência, ou ao menos de grande parte do esforço científico, "sempre esteve intimamente ligada ao capital. Ela preparou o caminho 
para ele" (GORZ, 2005, p. 12). Como o modelo econômico neoliberal prescreve a mínima presença e interferência do Estado, deixando tudo sob os ditames do mercado, a receita é "economizar mediante a privatização dos serviços públicos, do ensino, da saúde e da previdência social" (GORZ, 2005 , p. 11). Nesse onda de privatizações, grande parte da pesquisa científica é igualmente privatizada, o que objetiva " permitir à empresa que a realiza erguer um monopólio do conhecimento que proporcione um rendimento exclusivo" (GORZ, 2005, p. 11).

A ciência contribui, dessa forma, para o crescimento econômico e não para o desenvolvimento, pois acirra as desigualdades sociais ao concentrar ainda mais a riqueza nas mãos de poucos. Seguindo essa lógica, o capital busca engendrar estratégias para articular e colocar todas as forças produtivas a seu serviço. "A lógica do capital, da vida tornada capital, submete todas as atividades e espaços" (GORZ, 2005, p. 25).

Para resistir a essa subordinação, recriar-se e reproduzir-se, o campesinato desenvolve suas próprias estratégias, buscando manter sua autonomia e o seu protagonismo, passando a integrar um movimento denominado anti-globalização. Esse movimento é caracterizado pela "oposição enfática ao desmonte da coletividade, à modernização catastrófica dos países em desenvolvimento, à privatização do saber, da produção de conhecimento e do bem comum" (GORZ, 2005, p. 12).

O campesinato luta por um desenvolvimento integral, que restitua e/ou amplie a liberdade desfrutada pelas pessoas. A importância da liberdade é destacada por Gorz (2005, p. 12) ao afirmar que "a maior criatividade possível dos homens é atingida quando, livres da obrigação de tirar proveito e da disputa com a concorrência, eles podem desenvolver seu saber e suas capacidades de modo livre e cooperativo". Nesse sentido, "o computador aparece como um instrumento universal, universalmente acessível, por meio do qual todos os saberes e todas as atividades podem, em princípio, ser partilhados" (GORZ, 2005, p. 21).

A universalidade no acesso às TIC's, das quais o computador é apenas uma delas, é tranquilamente questionada quando se observa a realidade do campesinato. No campo possuir, por exemplo, um computador ou um telefone celular é uma coisa, mas acesso a internet ou o sinal de celular nem sempre está disponível. Em outros casos o campesinato não têm o conhecimento necessário para realmente apropriar-se da tecnologia, utilizá-la de forma adequada, extraindo o máximo de sua potencialidade a fim de torná-la uma aliada em suas atividades diárias. 
No campo, "as condições para a educação do povo e para o desenvolvimento da inteligência tem sido muito desfavoráveis nos últimos séculos. Aí a máquina não encontra por vezes o tipo de mão de obra de que necessita" (KAUTSKY, 1986, p. 43). A universalidade no acesso e pleno uso das TIC's, além de outros requisitos, passa por uma educação e uma formação de base, alinhada às necessidades e expectativas do público alvo. Entende-se que as TIC's tem potencial para gerar externalidades positivas ao permitir que o campesinato construa e/ou fortaleça suas redes de relacionamento e colaboração.

Para Gorz (2005, p. 21) as "externalidades positivas são sempre coletivamente úteis, beneficiam todos os indivíduos, não podem ser estabelecidas conforme o plano de uma empresa qualquer que ela seja, nem compradas por dinheiro algum, e nunca são convertidas em propriedade privada". Elas são favoráveis ao desenvolvimento porque seus benefícios são desfrutados pela maioria da sociedade, ou seja, é capaz de atingir todos os estratos sociais. Esse é o paradoxo entre desenvolvimento e o crescimento econômico a que se fez referência anteriormente. Embora não seja possível dissociar um do outro, nem sempre um crescimento significa desenvolvimento e nem sempre o desenvolvimento alavanca um crescimento.
O Produto Interno Bruto (PIB) representa o crescimento econômico obtido por um país, mas a sua evolução ou involução não implica, necessariamente, em desenvolvimento ou subdesenvolvimento.

A grande barreira na universalização das TIC's e a socialização das externalidades positivas produzidas, está nos interesses capitalistas. Um interesse do capital está no monopólio do conhecimento, para que não se torne um bem coletivo. Por isso, o capital busca monopolizar, apropriar-se da sua produção e controlar a todo custo sua disseminação. Segundo Gorz (2005, p. 37), "basta que o capital se aproprie dos meios de acesso ao conhecimento - especialmente os meios de acesso à internet - para conservar o controle sobre ele, para impedi-lo de se tornar um bem coletivo abundante". O controle sobre o acesso e os meios de acesso é o grande desafio.

Essa é a razão para, em pleno século XXI, haver, em especial no campo, a presença da exclusão digital, ou seja, pessoas excluídas da posse e/ou uso das TIC's. O mesmo capital que promoveu a exclusão social do campesinato ao longo do tempo, ao Ihe tirar a terra e levar-lhe à proletarização, expropriou-o e o explorou, agora está promovendo a sua exclusão digital. A exclusão digital é um processo engendrado pelo capital com o fito de controlar a produção e disseminação do conhecimento, 
concentrando o poder a ele inerente. Gorz (2005) assinala que

[...] o conhecimento é riqueza e fonte de riqueza sem ser, nem ter, um valor comercial, monetário. [...]. $\mathrm{O}$ conhecimento faz parte [...] dessas riquezas "externas" ou dessas "externalidades" que são indispensáveis ao sistema de produção de mercadorias; mas este é incapaz de produzi-lo segundo sua lógica e seus métodos próprios (GORZ, 2005, p. 56).

O conflito entre o capital e o campesinato agora se estende ao território imaterial, ao domínio do saber, inteligência, cultura, conhecimento e relacionamentos, enfim, das capacidades humanas. "O território imaterial está relacionado com o controle, o domínio sobre o processo de construção do conhecimento e suas interpretações. Portanto, inclui teoria, conceito, método, metodologia, ideologia etc." (FERNANDES, 2008, p. 210). O capital aumenta a capacidade para subordinar o campesinato ao minar a sua de resistência, enquanto o campesinato luta, resiste e busca manter sua autonomia e protagonismo. As capacidades humanas, experiências e conhecimentos presentes em cada unidade camponesa, uma vez socializados, podem ser customizados, aprimorados e tornarem-se fontes de riqueza, poder e emancipação. 0 que o capital busca é destruir ou apropriar-se desse conhecimento para fazê-lo operar a seu favor.

\section{CONSIDERAÇÕES FINAIS}

No campo as TIC's não tem contribuído para alavancar o desenvolvimento do campesinato. Ali não tem sido aportados os investimentos necessários para prover a infraestrutura e os equipamentos necessários, mas, acima de tudo, não estão sendo realizados os esforços para dotar o campesinato do conhecimento para aplicação das TIC's em suas atividades produtivas. Atualmente o domínio das TIC's é necessário para identificar, adquirir e operar máquinas, implementos e demais equipamentos adequados à realidade $\mathrm{e}$ necessidade da propriedade camponesa. Grande parte deles vem com esse tipo de tecnologia embarcada e requer a prévia obtenção de conhecimento e desenvolvimento de habilidades específicas e diferenciadas para operá-los. O domínio desse tipo de tecnologia ajudaria o campesinato a tornar-se relativamente independente de mão-de-obra alheia e estranha a sua unidade produtiva.

As TIC's podem contribuir também na formação de redes de colaboração próprias do campesinato, onde seja possível buscar e socializar experiências e conhecimentos. Essas redes podem conduzir a implementação de novas formas e modalidades de trocas, favorecendo o escoamento dos excedentes produtivos e a obtenção daquilo que a unidade camponesa 
necessita mas que não produz. A recuperação, desenvolvimento e compartilhamento das sementes crioulas, bem como as práticas agroecológicas do campesinato podem ser socializadas sem, muitas vezes, a necessidade de deslocamento e a incidência de grandes custos.

As TIC's e as redes podem também conduzir a uma maior organização, mobilização e resistência do campesinato contra as investidas do capital. As privações sofridas pelo campesinato e os desmandos cometidos pelo capital podem ser levados a conhecimento da sociedade sem a dependência de instituições governamentais ou meios de comunicação de massa, que encontram-se cooptados pelo capital. Os processos de invisibilização e criminalização historicamente engendrados sobre 0 campesinato podem ser melhor combatidos com o apoio das TIC's. Enfim, o próprio campesinato irá, com certeza, desenvolver outras estratégias e aplicações para as TIC's.

\section{REFERÊNCIAS}

BALTZAN, P.; PHILLIPS, A. Sistemas de Informação. Porto Alegre: AMGH, 2012.

BORDIEU, P. Escritos de Educação. NOGUEIRA, Maria Alice; CATANI, Afrânio (orgs.). 13 ed. Petrópolis: Vozes, 2012.

CHAYANOV, A. V. La Organización de la Unidad Económica Campesina. Buenos Aires: Ediciones Nueva Visión, 1974.

FELÍCIO, M. J. contribuição ao debate paradigmático da questão agrária e do capitalismo agrário. 2011. 214 fls. Tese (Doutorado em Geografia) - Faculdade de Ciências e Tecnologia/UNESP - Presidente Prudente, 2011.

FERNANDES, B. M. Conflitualidade e Desenvolvimento Territorial. In: BUAINAIN, A. M. (org.) Luta pela Terra, Reforma Agrária e Gestão de Conflitos no Brasil. Campinas: Unicamp, 2008, p. 173-230.

FERNANDES, B. M. Sobre a Tipologia de Territórios. In: SAQUET, M. A.; SPOSITO, E. S. (orgs.) Territórios e Territorialidades: teorias, processos e conflitos. São Paulo: Expressão Popular: UNESP - Programa de Pós-Graduação em Geografia, 2008, p. 197215.

GORZ, A. O Imaterial: conhecimento, valor e capital. Tradução: Celso Azzan Júnior. São Paulo: Annablume, 2005.

KAUTSKY, K. A Questão Agrária. São Paulo: Nova Cultural, 1986.

MOTTA, M. Dicionário da Terra. Rio de Janeiro: Civilização Brasileira, 2005.

PUTNAM, R. D. Comunidade e Democracia: a experiência da Itália moderna. 3. ed. Rio de Janeiro: FGV, 2002.

SHANIN, T. Campesinos y Sociedades Campesinas. Tradução: Eduardo L. Suárez. México: Fondo de Cultura Económica, 1979.

Recebido para publicação em 19/08/2015 Revisado em 08/09/2015

Aceito em 11/09/2015 